\title{
Study of occurrence of Multidrug Resistant Escherichia coli Clinical isolates as a result of Extended Spectrum Beta-Lactamase (Esbls) Production
}

\author{
Abba, P. O.*1 and Akor, J. O $^{2}$. \\ ${ }^{1}$ Research fellow, Department of Medical Microbiology and Parasitology, Benue State University Teaching \\ Hospital, Makurdi, Nigeria. \\ ${ }^{2}$ Academic Technologist, Department of epidemiology and community health, College of Health Sciences, \\ Benue State University, Makurdi, Nigeria.
}

\begin{abstract}
Resistance to antibiotics by microorganisms has increased dramatically in the past few years. Resistance to third generation cephalosporins and other classes of antibiotics is attributed to the production of beta-lactamase genes located on mobile genetic elements, which facilitate their transfer between different species. This study was undertaken to determine the presence of ESBLs in 400 isolates of Escherichia coli obtained from various clinical specimens (urine, stool, blood, wound swabs, sputum and throat swabs) collected from 216 female and 184 male patients attending various health facilities in Makurdi, Benue State, Nigeria; and to relate ESBL production with antibiotic resistance. Antibiotic susceptibility test using penicillin, ceftriaxone, ceftazidime, cefuroxime, cefotaxime, amoxicillin and clavulanic acid, gentamycin, chloramphenicol and imipenem antibiotic discs sourced from OXOID, USA was carried out, using NCCLS guidelines on the isolates. Presence of ESBLs was determined using the Double Disc Synergy (DDST) test. The isolates showed the highest resistance to penicillin 392(98\%) producing 62(15.8\%) ESBLs. Only 8 (2\%) isolates were susceptible to penicillin. This was closely followed by resistance to ceftriaxone (385; 96.3\%), producing 62(16.1\%) ESBLs. The isolates were also resistant to other classes of antibiotics: aminoglycosides (gentamycin) 331(82.7\%), carbapenem, imipenem 2(0.5\%) which was the least. Three hundred and ninety-eight (99.5\%) of the isolates were susceptible to imipenem. Isolates from blood specimens (26.3\%; $n=5)$ harboured the highest percentage of ESBLs, followed by isolates from wound swab specimens (17.3\%; $n=9)$. The study showed moderate production of ESBLs resulting in multiple antibiotic resistance.
\end{abstract}

Key words: Antibiotic resistance, ESBL, Escherichia coli, Beta-lactamase, Benue.

\subsection{INTRODUCTION}

Introduction of third generation cephalosporins in the early 1980s have been met with serious resistance by ESBL-producing Escherichia coli and other Gram-negative bacteria. This resistance came as a result of these bacteria's ability to produce mutated versions of beta-lactamase, called extended spectrum beta-lactamase (ESBL) which strengthened them to neutralize the activity of expanded-spectrum cephalosporins and monbactams $\left[{ }^{1}\right]$. ESBLs can be inhibited by clavulanic acid and tazobactam $\left[^{2}\right]$.

The production of ESBLs by entreobacteriacea has posed a serious public health problem Worldwide. The consequence of this is therapeutic failure in individuals that have been given inappropriate antibiotics. The matter is worsened by lack of sensitive diagnostic methods to guide therapy, monitor resistance development and implement intervention strategies $\left[{ }^{3}\right]$. Enterobacteriacea 
producing ESBLs show variable susceptibility patterns for aminoglycosides, fluoroquinolones and fourth generation cephalosporins $\left[{ }^{4}\right]$. Carbapenems are the only class of antibiotics active against ESBLs.

Genes encoding ESBLs are frequently found on the same plasmid as those encoding resistance to other classes of antibiotics such as aminoglycosides, fluoroquinolones and sluphonomides $\left[{ }^{1}\right]$. Selective pressure by use of second and third generations of cephalosporins favour the development of mutations that result in conformational changes in the active serine site of amino acid sequence of TEM and SHV enzymes [ $\left.{ }^{5}\right]$.

Previous use of $\beta$-lactam antibiotics and fluoroquinolones has been mentioned as risk factors to acquiring ESBL infections. These drugs constitute the drugs of choice for treatment of infections caused by Gram-negative organisms in the study area [ $\left.{ }^{6}\right]$. Previous studies in this region (North-central) revealed prevalence of $18.6 \%\left[{ }^{7}\right]$ and $16.0 \%$ in the study area $\left[{ }^{8}\right]$. With these varying records of prevalence of ESBL in the region it will be useful to know if antibiotics resistance is related to ESBL production by enterobacteriacea in the study population. Antibiotic susceptibility patterns of the isolates will aid clinicians to decide empiric treatment for infections caused by ESBL-producing microorganisms.

\subsection{MATERIALS AND METHODS}

A total of four hundred clinical specimens of urine $(n=200)$, stool $(n=110)$, blood $(n=19)$, sputum $(n=12)$, wound swabs $(n=52)$ and throat swabs $(n=7)$ collected from six selected health facilities grouped into tertiary, secondary and primary, after obtaining ethical clearance from institutions and consent from subjects, were used for the cross-sectional study. These specimens were inoculated on to various culture media to isolate Escherichia coli, which were identified by standard microbiological methods: colonial morphology, Gram's reaction, biochemical tests covering TSI, indole, and motility.

Antibiotic susceptibility testing was carried out using Kirby-Buaer disk diffusion method, using Mueller-Hinton agar according to BSAC guidelines. Antimicrobial agents used for susceptibility test were penicillin, ceftazidime, cefuroxime, cefotaxime, mipenem and ceftriaxone. Others included ciprofloxacin, gentamycin and chloramphenicol. The susceptibility break point was determined by measurement of zones of inhibition and compared with standards given by EUCAST (European Committee of Antimicrobial Susceptibility Testing).

Presence of extended spectrum beta-lactamase production (ESBL) was determined by inoculating the isolates on Mueller-Hinton agar and subjecting them to cefotaxime $(30 \mu \mathrm{g})$ and ceftazidime $(30 \mu \mathrm{g})$ antibiotic discs alone and in combination with amoxicillin and clavulanic acid $(10 \mu \mathrm{g})$ (Oxoid; Basingstoke, UK). The turbidity of respective bacterial suspensions of the bacterium was adjusted to 0.5 with McFarland standard. The plates were incubated at $37^{0} \mathrm{C}$ for 24 hours.

The results were interpreted according to guidelines of Clinical and Laboratory Standards Institute (CLSI), where interpretive criteria for ESBL activity was based on an increase of $\geq 5 \mathrm{~mm}$ in diameter of the inhibition zone around discs containing clavulanic acid as compared to diameters of the inhibition zone around discs that contained no clavulanic acid, which is a beta-lactamase inhibitor (CLSI, 2014).

\subsection{STATISTICAL ANALYSIS}

Data obtained from the research were tabulated and analyzed using SPSS version 20.0. Chi square was applied at $95 \%$ to test degree of association.

\subsection{RESULTS}

ESBL-producing Escherichia coli demonstrated highest resistance to penicillin $98 \%$ (n=392) with the production of 62 (15.8\%) ESBLs. Even the 2\% $(\mathrm{n}=8)$ that were susceptible to penicillin also produced 2 ESBLs. Resistance to cefotaxime was $92.8 \%$ $(\mathrm{n}=371)$ with production of 55 ESBLs $(14.8 \%)$. Susceptibility to cefotaxime was $7.2 \%(\mathrm{n}=29)$ showing a significant difference between resistance and susceptibility to cefotaxime $(\mathrm{p}=0.02)$. The isolates showed least resistance to mipenem $0.5 \%(\mathrm{n}=2)$ and highest susceptibility $99.5 \%(n=398)$. Up to 63 ESBLs were produced by 398 susceptible isolates, but these could not inactivate mipenem, a carbapenem, which are known to be stable in the presence of beta-lactamases (Table 1). There is no significant difference between susceptibility and resistance to mipenem $(\mathrm{p}=0.19)$.

Clinical isolates from blood specimens harboured more ESBLs $(26.3 \% ; n=5)$ than other specimens. This was followed by isolates from wound specimens $17.3 \%(n=9)$. Throat swab isolates harboured no ESBLs $(0 \%$; $n=0)$ (Table 2). 
International Journal of Advances in Scientific Research and Engineering (ijasre), Vol 6 (6), June -2020

Table 1: Occurrence of ESBL-producing Escherichia coli clinical isolates according to Antibiotic susceptibility profile

\begin{tabular}{|c|c|c|c|c|c|}
\hline \multirow[b]{2}{*}{ Antibiotic } & \multicolumn{2}{|c|}{ ESBL detection } & \multirow[b]{2}{*}{ Number positive (\%) } & \multirow[b]{2}{*}{$\chi^{2}$} & \multirow[b]{2}{*}{$P$ value } \\
\hline & Susceptibility & Number (\%) & & & \\
\hline & Susceptible & $8(2.0)$ & $2(25.0)$ & & \\
\hline Penicillin & Resistant & 392(98.0) & $62(15.8)$ & & \\
\hline \multirow{4}{*}{ Ceftriaxone } & Total & $400(100.0)$ & $64(16.0)$ & 0.49 & 0.48 \\
\hline & Susceptible & $15(3.7)$ & $2(13.3)$ & & \\
\hline & Resistant & $385(96.3)$ & $62(16.1)$ & & \\
\hline & Total & $400(100.0)$ & $64(16.0)$ & 0.82 & 0.77 \\
\hline \multirow{3}{*}{ Cefuroxime } & Susceptible & $24(6.0)$ & $5(20.8)$ & & \\
\hline & Resistant & $376(94.0)$ & $59(15.7)$ & & \\
\hline & Total & $400(100.0)$ & $64(16.0)$ & 0.44 & 0.51 \\
\hline \multirow{3}{*}{ Cefotaxime } & Susceptible & $29(7.2)$ & $9(31.0)$ & & \\
\hline & Resistant & $371(92.8)$ & $55(14.8)$ & & \\
\hline & Total & $400(100.0)$ & $64(16.0)$ & 5.26 & 0.02 \\
\hline \multirow{3}{*}{ Chloramphenicol } & Susceptible & $52(13.0)$ & $7(13.5)$ & & \\
\hline & Resistant & $348(87.0)$ & $57(16.4)$ & & \\
\hline & Total & $400(100.0)$ & $64(16.0)$ & 0.29 & 0.59 \\
\hline \multirow{3}{*}{ Ciprofloxacin } & Susceptible & $64(16.0)$ & $12(18.8)$ & & \\
\hline & Resistant & $336(84.0)$ & $52(15.5)$ & & \\
\hline & Total & $400(100.0)$ & $64(16.0)$ & 0.43 & 0.51 \\
\hline \multirow{3}{*}{ Ceftazidime } & Susceptible & $67(16.8)$ & $12(17.9)$ & & \\
\hline & Resistant & $333(83.2)$ & $52(15.6)$ & & \\
\hline & Total & $400(100.0)$ & $64(16.0)$ & 0.22 & 0.64 \\
\hline \multirow{3}{*}{ Gentamycin } & Susceptible & $69(17.3)$ & $15(21.7$ & & \\
\hline & Resistant & $331(82.7)$ & $49(14.8)$ & & \\
\hline & Total & $400(100.0)$ & $64(16.0)$ & 2.04 & 0.15 \\
\hline \multirow{3}{*}{ Mipenem } & Susceptible & 398(99.5) & $63(15.8)$ & & \\
\hline & Resistant & $2(0.5)$ & $1(50.0)$ & & \\
\hline & Total & $400(100.0)$ & $64(16.0)$ & 1.73 & 0.19 \\
\hline
\end{tabular}


International Journal of Advances in Scientific Research and Engineering (ijasre), Vol 6 (6), June -2020

Table 2: Distribution of ESBL-producing Escherichia coli isolates by clinical specimens

\begin{tabular}{llll}
\hline Specimen & \multicolumn{2}{c}{ ESBL DETECTION } & \\
& Number positive (\%) & Number negative(\%) & $\begin{array}{l}\text { Total number } \\
\text { examined (\%) }\end{array}$ \\
\hline Blood & $5(26.3)$ & $14(73.7)$ & $19(100)$ \\
Wound swabs & $9(17.3)$ & $43(82.7)$ & $52(100.0)$ \\
Urine & $33(16.5)$ & $167(83.5)$ & $200(100.0)$ \\
Stool & $16(14.5)$ & $94(85.5)$ & $110(100.0)$ \\
Sputum & $1(8.3)$ & $11(91.7)$ & $12(100.0)$ \\
Throat swabs & $0(0.0)$ & $7(100)$ & $7(100.0)$ \\
& & & $400(100.0)$ \\
\hline
\end{tabular}

$\chi^{2}=3.64 ; \mathrm{df}=5 ; \mathrm{p}=0.60$

Key:

$\mathrm{ESBL}=$ Extended Spectrum Beta-lactamase

\subsection{DISCUSSION}

Infections resulting from antibiotic resistant bacteria are more difficult and, in some instances, impossible to treat with current available antibiotics. Such infections lead to higher morbidity and mortality, imposing huge healthcare cost $\left[^{9}\right]$. Bacterial resistance to two or more classes of antibiotics occur as a result of selective pressure or horizontal gene transfer.

The current study showed high level of resistance to various classes of antibiotics by Escherichia coli bacterium isolated from various clinical specimens with resistance to penicillin $(98 \% ; n=392)$ being the highest, and the least resistance to mipenem $(0.5 \%, \mathrm{n}=2)$. Other researchers have previously recorded high resistance of Escherichia coli isolates to penicillin, which support the finding of this work: $\left[{ }^{10}\right]$ reported 80 to $100 \%$ resistance to ESBL-producing E. coli. $\left[{ }^{12}\right]$ reported $0 \%$ resistance to mipenem in Australia, which agreed with the findings of the present study. Resistance to fluoroquinolone class of antibiotics was also high. Resistance to ciprofloxacin for instance was $84 \%$ (336). This corroborates with $\left[{ }^{13}\right]$ who reported $93 \%$ resistance to ciprofloxacin in Dhaka city.

Ability of Escherichia coli to produce extended spectrum beta-lactamases (ESBLs) makes them more resistant. $\left[{ }^{14}\right]$ reported that large amounts of ESBLs in the periplasmic space either bind or slowly hydrolyze the antibiotic before it reaches its target. Sixtyfour (64) out of 400 isolates of various specimens produced ESBLs in the present study (Table 2). Isolates from blood specimens harboured more ESBLs, $26.3 \%$ (5) than 5 other specimens. This finding is contrary to the report of $\left[{ }^{15}\right]$ who recovered most ESBLs from isolates of urine specimens $(60.3 \%$; 35) in Enugu, South East Nigeria. Throat swab specimens carried no ESBLs, $0 \%$ (0). There was no significant difference between ESBL production and clinical specimens $\left(\chi^{2}=3.64 ; p=0.60\right)$. Previous use of antimicrobial agents, especially cephalosporins and quinolones has been reported as risk factors for ESBLs [ $\left.{ }^{16}\right]$. These agents constitute the drug of choice for treating infections with Gram-negative bacteria in Nigeria $\left[{ }^{17}\right]$

\subsection{CONCLUSION}

The isolates of Escherichia coli studied exhibited multidrug resistance. Highest resistance was to penicillin, a beta-lactam. Ciprofloxacin from the fluoroquinolone class was also strongly resisted $(84 \%$; 336); gentamycin (aminoglycoside) was equally resisted $(82.7 \%$; 331). Extended spectrum beta-lactamase (ESBL) was expressed by $16 \%$ of the isolates. ESBL production may contribute to high resistance of Escherichia coli to antimicrobial agents. Mipenem, a carbapenem is the most active antimicrobial agent for the treatment of ESBL-producing strains of Escherichia coli. 
International Journal of Advances in Scientific Research and Engineering (ijasre), Vol 6 (6), June -2020

\section{Authors' contribution}

Abba P.O. conceived, designed and executed the research; Akor J.O supervised data collection, analyzed data and supervised manuscript writing. Both authors read and accepted the final manuscript.

\section{Conflict of interest}

The authors declared that they have no conflict

\section{Acknwoledgements}

The authors thank the management of Benue State University Teaching Hospital, Makurdi for granting ethical clearance for conducting this research in their Microbiology laboratory. They also thank the nursing staff of the hospital for preparing the patients for sample collection and finally appreciate the laboratory staff of Microbiology Department for their technical assistance.

\section{REFERENCES}

1. D. M. Livermore, "Fourteen years in resistance", International Journal of Antimicrobial Agents, 2012 (39): $283-294$.

2. D.L. Paterson and R.A. Bonomo, "Extended spectrum beta-lactamse: a clinical up date", Clinical Microbio. Rev., 2005, 18:657-686.

3. E. Sturenburg, and D. Mack, "Extended Spectrum Beta- lactamases: implications for the clinical microbiology laboratory", Journal of Infection, 2003, 47: 273 - 95.

4. E. Lautenbach, J. B. Patel, W. B. Buker, P. H. Edelstein and N. O. Fishman,

"Extended - spectrum Beta- lactamases - producing Escherichia coli and Klebsiella pneumoniae. Risk factors for infection and impact on resistance of outcome" Clinical Infectious Disease, 2001, 32: 1162 - 1171.

5. D. Szabo, I. Bais, and F. Rozgomyi, "Extended spectrum b-lactamase: an actual problem of hospital microbiology (a review)", Acta Microbiol. Immunol. Hung. 1997, 44: 309-325.

6. D.O. Ogbolu, O.A Daini, A. Ogunledun, A.O. Alli, and M.A. Webber, "High levels of multidrug resistance in clinical isolates of Gram-negative pathogens from Nigeria”, International Journal of Antimicrobial Agents, Elsevier, 2010,37 (1): 62.

7. K.I. Onyedibe, E.O. Shobowale, M.O. Okolo, M.O. Iroezindu, T.O. Afolaranmi, F.O. Nwaokorie, S.O. Opajobi, S.E.Isa, and D.Z. Egah, "Low Prevalence of Carbapenem Resistance in Clinical Isolates of Extended Spectrum Beta Lactamase (ESBL) Producing Escherichia coli in North Central, Nigeria”, Advances in Infectious Diseases, 2018, (8): 109-120.

8. P. O. Abba, E. U. Umeh, G. M. Gberikon, and E. B. Agbo, "Prevalence of Extended Spectrum Beta-Lactamase-Producing Escherichia coli Isolated from Selected Health Facilities in Makurdi. International Journal of Research and Innovation in Applied Science”, 2019, 4(7): 2454-6194

9. K. E. Kollef, G. E. Schramm, A. R. Wills, R. M. Reichley, S. T. Micek, and H. M. Kollef, "Predictors of 30-day mortality and hospital costs in patients with ventilator associated pneumonia attributed to potentially antibiotic-resistant gram negative bacteria" Chest Journal, 2008, 134(2):281-7.

10. M. S. Islam, and M.A. Yusuf, "Extended spectrum beta lactamase producing uropathogenic E. coli infection in Dhaka Bangladesh", Journal Of Bacteriology Research, 2014, 7: 1-7

11. E. E. Okwori, S.I. Nwadioha, E.O.P. Nwokedi, M. Odimayo, and G.T.A. Jombo, "Bacterial pathogens and their antibiotic susceptibility pattern in Idoma Community, Benue state of Nigeria”, International Journal of Infectious Diseases, 2011, 1(5): 6-8

12. S. Hassan, S. A. Jamal, and M. Kamal, "Occurrence of multidrug resistant and ESBL-producing E. coli causing urinary tract infections", Australian Journal of Basic and Applied Sciences, 2011, 7: 39-43.

13. R. Farzana, S.M. Shamsuzzaman, K. Z. Mamun, and P. Shears, “Antimicrobial susceptibility pattern of extended spectrum blactamase producing gram-negative bacteria isolated from wound and urine in a Tertiary care Hospital, Dhaka city, Bangladesh", Southeast Asian Journal of Tropical Medicine and Public Health, 2013, 44(1):96-103 
International Journal of Advances in Scientific Research and Engineering (ijasre), Vol 6 (6), June -2020

14. G. A. Jacoby, and L. Sutton, "Beta-lactamases and Betalactam resistance in Escherichia coli", Antimicrobial Agents and Chemotherapy, 1985, 28(5): 703-705.

15. I.R Iroha, E.S. Amadi, A.E. Oji, A.C. Nwuzo and P.C. Ejike-Ugwu, "Detection of Plasmid Borne ESBL Enzymes from Blood and Urine Isolates of Gram Negative Bacteria from a University Teaching Hospital in Nigeria", Current Research in Bacteriology, 2010, (3): 77-83.

16. J. D. Knudsen, and S. E. Andersen, "A multi-disciplinary intervention to reduce infections of ESBL- and AmpC-producing Gram negative bacteria at a university hospital”, PLOS ONE; 2014, 9 (1): 86457.

17. I.N. Okeke, A. Lamikaran, and R. Edelman, "Socio-economic and behavioral factors leading to acquired bacterial resistance to antibiotics in developing countries", Emerging Infectious Disease, 19995, (1): 18 - 27.

*Corresponding Author: Abba P. O.

Tel: +2348o34056504; e- mail: ogorpaul1969@gmail.com 